\title{
OPTIMALISASI APLIKASI E-COMMERCE SHOPEE FOOD SEBAGAI MEDIA PEMASARAN UMKM DI MASA PANDEMI COVID 19.
}

\author{
Adhita Maharani Dewi \\ Universitas Kristen Surakarta \\ Jl. W. Mongisi, 36-36 Surakarta. \\ Email : mawarsharon2012@gmail.com. \\ http://dx.doi.org/10.21460/jrmb.2021.162.393
}

\begin{abstract}
ABSTRAK
Dampak pandemic Covid 19 mengakibatkan banyak perusahaan gulung tikar, sehingga terpaksa melakukan pemutusan hubungan kerja terhadap karyawan. Sisi positif dari pemutusan hubungan kerja, muncul UMKM baru yang bergerak dibidang kuliner. Pemasaran yang dilakukan oleh UMKM melibatkan e-commerce. Salah satu e-commerce yang konsisten melakukan perubahan terhadap fitur fiturnya adalah Shopee. Ditahun 2020 Shopee meluncurkan fitur baru yaitu Shopee food. Lewat fitur ini UMKM bisa mendaftar sebagai penjual. Shopee food menawarkan beberapa kemudahan bagi konsumen maupun penjual. Tujuan penelitian ini untuk mengetahui sejauh mana peran ecommerce shopee food sebagai media pemasaran bagi UMKM dimasa pandemic covid 19. Penelitian ini dilakukan dengan menyebarkan kuesiner melalui google form. Varibel X dalam penelitian ini adalah diskon, cash back dan shopee pay. Sedangkan variable Y adalah Keputusan Pembelian. Varibel X memberikan pengaruh yang positif terhadap keputusan pembelian. Hasil dari penelitian ini variabel yang paling dominan adalah diskon. Toko yang memberikan diskon secara berkesinambungan akan menimbulkan minat beli konsumen yang lebih tinggi.
\end{abstract}

Kata kunci : keputusan pembelian, diskon, cash back, shopee pay.

\begin{abstract}
The impact of the Covid-19 pandemic has resulted in many companies going out of business, so they were forced to lay off their employees. The positive side of the termination of employment, new MSMEs are emerging that are engaged in the culinary field. Marketing carried out by MSMEs involves e-commerce. One of the e-commerce companies that consistently makes changes to its features is Shopee. In 2020 Shopee launched a new feature, namely Shopee food. Through this feature, MSMEs can register as sellers. Shopee food offers several conveniences for consumers and sellers. The purpose of this study was to determine the extent of the role of shopee food e-commerce as a marketing medium for MSMEs during the covid 19 pandemic. This research was conducted by distributing questionnaires via google form. X variables in this study are discounts, cash back and shopee pay. While the variable $\mathrm{Y}$ is the Purchase Decision. Variable $\mathrm{X}$ has a positive influence on purchasing decisions. The result of this research is the most dominant variable is discount. Stores that provide discounts on an ongoing basis will lead to higher consumer buying interest.
\end{abstract}

Keywords: buying decision, discount, cash back, shopee pay. 


\section{PENDAHULUAN,}

Teknologi informasi yang berkembang dengan pesat sangat memudahkan manusia untuk mendapatkan informasi yang diperlukan dalam hitungan detik. Beberapa tahun belakangan ini banyak sekali ecommerce yang masuk ke Indonesia, hal ini tentu saja menyebabkan perubahan yang baik disegala sektor ekonomi. Salah satu ecommerce yang masuk adalah Shopee, yang masuk ke Indoenisa pada tahun 2015. Shopee pada awalnya hanya memiliki beberapa fitur penjualan saja, hingga akhirnya berkembang dan mempunyai fitur Shopee Food.

Dalam kurun waktu beberapa tahun, jumlah penjual dan pembeli yang mendownload aplikasi Shopee di Indonesia semakin meningkat, mencapai angka 50 juta, hal ini membuktikan bahwa Shopee sangat digemari dinegara ini. Dimasa pandemi Covid 19, tidak sedikit perusahaan yang melakukan pemberhentian kerja terhadap karyawannya. Desakan akan kebutuhan hidup dan efek dari PHK maka banyak orang yang beralih dari pegawai menjadi pengusaha. Salah satu usaha yang digemari adalah kuliner, dengan alasan modal untuk memulai bisnis kuliner tidak begitu banyak. Pengusaha kuliner pemula dapat memanfaatkan dapur dan peralatan dapurnya sendiri untuk memulai berbisnis, setelah menemukan produk apa yang akan dijual, kemudian akan timbul permasalahan bagaimana cara menjual produk tersebut.

Cara penjualan produk UMKM yang banyak digunakan adalah melalui media sosial. Sekarang ini pemasaran tidak hanya melalui media sosial saja, akan tetapi sudah merambah ke ecommerce. Hal baru ini tentu saja membuat pelaku UMKM harus belajar lagi, banyaknya ecommerce yang bermunculan menyebabkan produk UMKM menjadi mudah dibeli dan dijangkau oleh konsumen. Kehadiran Ecommerce di Indonesia telah membuat perubahan pada perilaku konsumen yang semula hanya berbelanja secara offline dengan dating langsung ke pusat perbelanjaan, pasara maupun toko sekarang dapat dengan mudah dilakukan secara online dirumah. Perubahan perilaku ini banyak dipengaruhi oleh persepsi para pelanggan mengenai jarak, harga, 80 promosi, tempat yang telah ditetapkan oleh perusahaan selama ini. (Kotler dan Keller, 2019).

Salah satu ecommerce yang masuk ke Indonesia adalah Shopee. Perusahaan ini berada di Indonesia sejak tahun 2015. Walaupun terhitung baru, akan tetapi sudah berhasil mengambil hati rakyat Indonesia, hal ini terbukti dengan jumlah orang yang mendownload aplikasi Shopee di play store, kian hari kian bertambah. Sejak pandemic Covid 19 melanda dunia, Shopee mulai memikirkan konsep fitur baru, salah satunya adalah Shopee Food yang launching di Indonesia sejak April 2020 (https://www.ekrut.com/media/shopee-foodsegera-ekspansi-ke-indonesia).

Pelaku UMKM bisa mendaftarkan tokonya dengan mudah ke Shopee food. Ketika toko sudah terdaftar maka akan memudahkan konsumen dalam melakukan pembelian. Fitur diskon, cash back dan shopee pay merupakan daya tarik tersendiri dari Shopee food. Diskon adalah pengurangan langsung dari harga barang pada pembelian selama satu periode yang waktu dinyatakan. Dalam Shopee food, toko atau penjual yang akan memberikan diskon, terlebih dahulu harus menghubungi pihak Shopee untuk ketentuan diskon yang akan diberikan kepada konsumen. Misalnya diskon $20 \%$ untuk ongkos kirim, diskon $50 \%$ jika konsumen melakukan pembelanjaan senilai serratus ribu rupiah. Besarnya diskon bisa ditentukan oleh pihak penjual. Selain itu Shopee juga menawarkan parade diskon pada kurun waktu tertentu kepada para penjual dengan tujuan agar konsumen melakukan pembelian ulang atau repeat order.

Cash back adalah suatu penawaran yang mana para pembeli akan diberikan persentase pengembalian uang, baik itu secara tunai atau virtual, atau bisa juga berbentuk produk tertentu, dengan memenuhi suatu persyaratan pembelian yang sudah ditentukan oleh pihak toko atau pihak penyelenggara cashback tersebut. (https://accurate.id/marketingmanajemen/cashback-adalah/). Di Shopee banyak sekali penawaran cashback yang diberikan oleh merchant. Diantara cash back berupa deposit poin, jika konsumen melakukan pembelian tertentu maka akan mendapatkan 
point cash back sesuai dengan peraturan yang sudah ditetapkan. Point cash back ini nanti akan masuk ke akun Shopee konsumen, kemudian bisa digunakan untuk membayar pembelanjaan lewat Shopee. Cash back merupakan salah satu daya tarik dari Shopee untuk menjaring konsumen agar melakukan pembelian terus menerus. Dengan adanya cash back konsumen merasa diuntungkan, karena nilai harga yang mereka bayar lebih murah dibandingkan dengan melakukan pembayaran tunai.

Shopee Pay merupakan fitur yang dikemabang oleh Shopee untuk memudahkan konsumen dalam melakukan pembayaran. Selain itu hal yang menarik dari Shopee pay ini adalah konsumen bisa mendapatkan harga yang lebih murah dibandingkan harga pasaran. Sebagai contoh Kopi Kenangan memberikan potongan harga sebesar $50 \%$ dengan syarat pembayaran order dilakukan dengan Shopee pay. Adanya fitur Shopee pay sangat menguntungkan untuk penjual dan pembeli.

Promosi, kepercayaan, kemudahan penggunaan dan pengalaman berpengaruh terhadap minat penggunaan Shopeepay (Fitriani, 2021). Sedangkan (Fitri, 2021) dalam penelitiannya mengatakan promosi dan cashback memiliki pengaruh positif terhadap minat beli mahasiswa melalui Shopee. Dalam penelitian (Rahmatika, 2020) menyatakan bahwa kemudahan dalam penggunaan teknologi paylater oleh pengguna e-commerce Indonesia sangat baik sekali serta pengguna paylater cenderung melakukan impulse buying saat berbelanja.

Berdasarakan pemaparan diatas, maka dilakukan penelitian tentang Optimalisasi Aplikasi Ecommerce Shopee Food Sebagai Media Pemasaran UMKM di Masa Pandemi Covid 19. Tujuan dari peneltiian ini untuk mengetahui apakah aplikasi shopee food dapat digunakan untuk meningkatkan pembelian dimasa pandemic covid 19. Penulis berharap dari penelitian ini UMKM yang ada dan sedang berkembang dapat menggunakan aplikasi shopee food sebagai media pemasaran dan mengoptimalisasi aplikasi tersebut.

\section{KAJIAN LITERATUR DAN HIPOTESIS}

\section{Minat Beli Konsumen}

80
Minat beli diperoleh dari suatu proses belajar dan proses pemikiran yang membentuk suatu persepsi dibenak konsumen. MInat beli menciptakan motivasi yang terus menerus terekam dalam benak konsumen dan menjadi keinginan yang sangat kuat ketika akhirnya konsumen memutuskan untuk melakukan pembelian. Menurut Kotler, et.al (2019) minat beli adalah perilaku konsumen yang muncul sebagai respon terhadap objek yang menunjukkan pelanggan untuk melakukan pembelian.

Ada beberapa faktor yang mempengaruhi minat beli konsumen, yaitu (Kotler, et.al 2019) :

1. Budaya (culture, sub culture, dan social classes);

2. Sosial (kelompok acuan, keluarga, serta peran dan status);

3. Pribadi (usia dan tahapan daur hidup, pekerjaan dan keadaan ekonomi, kepribadian, dan konsep diri, serta gaya hidup dan nilai);

4. Psikologis (motivasi, persepsi, pembelajaran, emotions, memory).

Faktor - faktor diatas secara tidak langsung dapat mempengaruhi minat beli seseorang terhadap suatu merek atau produk tertentu.

\section{Keputusan Pembelian}

Menurut Kotler (2009) keputusan membeli yaitu beberapa tahapan yang dilakukan oleh konsumen sebelum melakukan keputusan pembelian suatu produk. Dapat disimpulkan bahwa keputusan pembelian didorong oleh adanya kebutuhan atau keingan individu untuuk mengkonsumsi suatu barang atau jasa yang didasarkan kepada pilihan-pilihan alternatif yang telah dievaluasi terlebih dahulu. 7 Keputusan untuk membeli dapat mengarah kepada bagaimana proses dalam pengambilan keputusan tersebut dilakukan. Menurut Kotler dan Keller (2009:184) proses pembelian yang rumit biasanya melibatkan beberapa keputusan, suatu keputusan melibatkan pilihan diantara beberapa alternative tindakan atau perilaku, pada intinya walaupun pemasar sering mengacu pada pilihan antara produk, merek dan tempat pembelian, proses pembelian juga biasanya 
dipengaruhi dengan hubungan baik antara produsen.

\section{Pemasaran}

Pemasaran adalah mencari tahu apa yang diingikan pelanggan dan menyesuaikan produk perusahaan untuk memenuhi persyaratan tersebut, dan dalam prosesnya menghasilkan keuntungan bagi perusahaan (Westwood, 2010). Pemasaran adalah proses dimana perusahaan melibatkan pelanggan, membangun hubungan pelanggan yang kuat, dan menciptakan nilai untuk pelanggan dan mendapatkan nilai dari pelanggan sebagai imbalan (Kotler, 2020). Pemasaran adalah tentang mengedukasi orang - orang di pasar "tertentu" bahwa bisnis Anda dapat menyelesaikan masalah mereka, mengisi kekosongan mereka, atau mencapai peluang, harapan, dan tujuan dnegan cara yang tidak bisa dilakukan oleh bisnis lain (Abraham, 2010).

\section{Ecommerce}

Ecommerce adalah suatu proses membeli dan menjual produk - produk secara elektronik oleh konsumen dan dari perusahaan ke perusahaan dengan computer sebagai perantara transaksi bisnis. Media yang dapat digunakan dalam aktivitas e-commerce adalah world wide web internet (Laudon dan Laudon, 1998). Penggolongan e-commerce menurut Laudon dan Laudon (2008) dibedakan sebagai berikut :

1. Business to Consumer (B2C) : menjual barang dan jasa secara online kepada konsumen akhir. Saat ini konsumen dapat membeli hampir segala hal secara online seperti pakaian, kosmetik, tiket pesawat, komputer, mobil, dll.

2. Business to business (B2B) : menggunakan situs web B2B, e-mail, katalog produk online, dan sumber daya online lainnya untuk menjangkau pelanggan bisnis baru, melayani pelanggan saat ini dengan lebih efektif, dan meraih efisiensi pembelian dan harga yang lebih baik.

3. Consumer to Consumer $(\mathrm{C} 2 \mathrm{C})$ : pertukaran barang dan informasi secara online antara konsumen akhir. Dalam beberapa kasus saat ini, internet menyediakan alat yang sangat baik di mana konsumen dapat membeli atau menukarkan barang atau informasi secara langsung satu sama lain. Misalnya, eBay, Amazon.com, Kaskus.co.id, Olx.co.id, dll.

4. Peer - to - peer (P2P) : Sebuah teknologi yang memungkinkan pengguna internet untuk mengirim data secara langsung tanpa harus ke web server terlebih dahulu.

5. Mobile Commerce (M-Commerce) : Menggunakan media tanpa kabel untuk bertransaksi melalui media internet.

Electronic commerce atau lebih dikenal dengan nama e-commerce jika diartikan secara bahasa berarti perdagangan elektronik. Menurut Laudon dan Traver (2014), ecommerce merupakan transaksi yang terjadi melalui internet, web, ataupun perangkat seluler. Sedangkan menurut Zwass (1996), ecommerce merupakan wadah untuk berbagai informasi mengenai bisnis, menjalin serta menjaga hubungan bisnis,juga tempat untuk menjalankan transaksi bisnis itu sendiri dengan bantuan jaringan telekomunikasi.

\section{Diskon}

Membeli barang atau berbelanja dengan harga khusus yang lebih murah merupakan impian banyak konsumen. Setiap toko untuk meningkatkan penjualan pasti akan memberikan diskon kepada pembeli dengan prasyarat tertentu. Ada beberapa pengertian diskon menurut para ahli. Menurut Kotler (2019) diskon adalah pengurangan langsung dari harga barang pada pembelian selama satu periode yang waktu dinyatakan. Sedangkan menurut Tjiptono (2007) diskon merupakan potongan harga yang diberikan oleh penjual kepada pembeli sebagai penghargaan atas aktivitas tertentu dari pembeli yang menyenangkan bagi penjual. Jadi diskon merupakan penguarangan harga yang diberikan oleh penjual kepada konsumen untuk menarik minat beli terhadap suatu produk dalam periode yang telah ditentukan.

Dalam Kotler (2019) membagi jenis - jenis diskon sebagai berikut :

1. Diskon tunai : penurunan harga bagi pembeli yang segera membeyar tagihan.

2. Diskon Kuantitas : penurunan harga bagi pembeli yang membeli dalam jumlah besar. 
3. Diskon fungsional : diskon ditawarkan produsen kepada angota saluran perdagangan jika mereka melakukan fungsi tertentu, seperti menjual, menyimpan, atau melakukan pencatatan.

4. Diskon musim : penurunan harga untuk orang yang membeli barang atau jasa diluar musim.

5. Potongan harga : pembayaran ekstra yang dirancang untuk memperoleh partisipasi penjual ualng dalam program khusus .

\section{Cash back}

Pengertian cash back (Zainuddin, 2019) adalah daya tarik yang dapat dilakukan dalam meningkatkan volume penjualan yaitu dengan mengiming - imingi konsumen atas pengembalian sejumlah perorbanan yang dilakukan dengan syarat tertentu. Cash back bisa diberikan dalam bentuk potongan harga jual untuk konsumen maupun point penjualan.

\section{Shopee pay}

Shopee pay adalah fitur yang terdapat dalam aplikasi Shopee dan bisa digunakan untuk melakukan pembayaran online. Shopee menggunakan fitur shopeepay sebagai salah satu alat pembayaran pembelian yang dapat digunakan oleh semua pengguna aplikasi. Shopeepay adalah salah satu fitur pembayaran digital yang ada di Shopee. Penggunaan shopeepay ini tidak hanya untuk membeli makanan saja, akan tetapi bisa digunakan untuk membayar pembelanjaan dan tagihan yang ada di aplikasi Shopee. Seperti melakukan pembelian pulsa PLN, Telkom, PDAM, Voucher data, dan sebagainya. Selain itu beberapa toko merchant shopee juga menggunakan QR Code untuk memudahkan konsumen dalam proses pembayaran. Konsumen tinggal melakukan scan QR dan kemudian terhubung dengan aplikasi Shopee. Hal ini memudahkan konsumen dalam melakukan pembayaran, apalagi dimasa pandemic covid 19, sangat disarankan sekali menggunakan Shopee sebagai sarana pembayaran karena tidak terjadi kontak fisik antara konsumen dengan penjual. Kemudahan digital payment lewat shopeepay juga didukung dengan keuntungan lainnya, yaitu konsumen mendapatkan promo dan diskon jika melakukan pembayaran menggunakan shopeepay.

\section{Kerangka Penelitian}

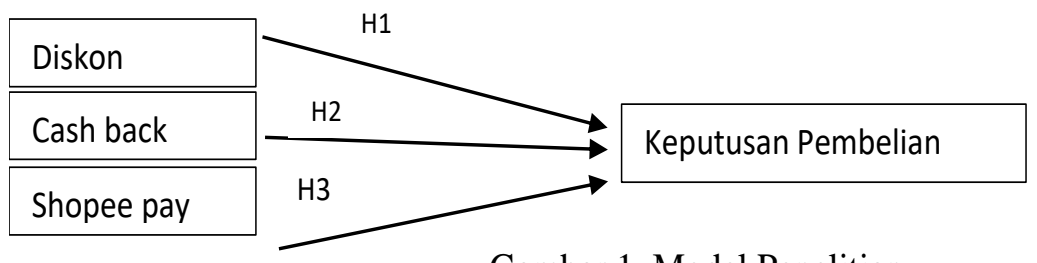

Gambar 1. Model Penelitian

\section{Hipotesis}

Konsumen akan lebih tertarik melakukan pembelian jika sebuah toko memberikan diskon terhadap barang yang dijual. Penelitian Adil Fadilah dan Rini Syarif (2013) menyatakan bahwa diskon memiliki pengaruh yang significant terhadap keputusan pembelian. Penelitian Zainuddin (2019) menyatakan bahwa cash back memiliki pengaruh yang dominan terhadap minat beli konsumen. Selanjutnya penelitian Rahmatika Sari (2020) menyatakan bahwa paylater memberikan pengaruh yang positif terhadap implusive buying. Hipotesis dapat dirumuskan sebagai berikut:

$\mathrm{H}_{1}$ : diskon berpengaruh positif terhadap keputusan pembelian. 
$\mathrm{H}_{2}$ : cash back berpengaruh positif terhadap keputusan pembelian.

$\mathrm{H}_{3}$ : Shopee pay berpengaruh positif terhadap keputusan pembelian.

\section{METODA PENELITIAN}

Dalam melakukan penelitian salah satu hal yang penting adalah menentukan metode dan pendekatan penelitian yang dilakukan. Metode penelitian yang digunakan dalam penelitian ini adalah pendekatan kuantitaif. Menurut, Azwar (2012) menjelaskan bahwa penelitian kuantitaif adalah penelitian yang semua informasi atau data diolah dalam bentuk angka dengan metode statistika. Desain penelitian kuantitatif yang digunakan untuk menjelaskan fenomena variable yang diteliti akan bersifat eksplanatif. Penelitian yang bersifat eksplanatif dapat menjelaskan hubungan kausal antara variable yang mempengaruhi hipotesis (Sugiyono, 2017). Desain ekspanatif dalam penelitian ini akan menggambarkan optimalisasi shoopefood sebagai media pemasaran.

Menurut Sugiyono (2017), populasi adalah wilayah generalisasi yang terdiri atas obyek atau subyek yang mempunyai kualitas dan karakteristik tertentu yang ditetapkan oleh peneliti untuk dipelajari dan kemudian ditarik kesimpulannya. Populasi dari penelitian ini adalah adalah konsumen Shopee food, dengan kriteria memiliki aplikasi Shopee dan sudah pernah melakukan pembelian melalui fitur shopee food minimal sebanyak 2 kali. Populasi dalam penelitian ini tidak terbatas karena tidak diketahui jumlah banyaknya populasi. Teknik yang digunakan dalam penelitian ini yaitu purposive sampling, teknik penentuan sampel dengan suatu hal yang dipertimbangkan (Sugiyono, 2017) sedangkan hal yang dipertimbangkan adalah masyarakat yang memiliki aplikasi Shopee dan pernah melakukan pembelian melalui fitur Shopee food minimal dua kali. Responden berjumlah 100 orang.

Teknik pengumpulan data dengan cara mneyebarkan kuesioner melalui google form. Kuesioner yaitu seperangkat pertanyaan atau pernyataan tertulis kepada responden untuk dijawabnya (Sugiyono,2017). Menurut Suwartono (2014) kuesioner tertutup adalah jenis kuesioner yang terdiri dari jumlah butir 82 pertanyaan atau pernyataan dengan jumlah opsi yang ditentukan. Dalam penelitian ini menggunakan kuesioner tertutup yang menyediakan pertanyaan atau pernyataan dengan jumlah opsi yang telah ditentukan. Responden diminta untuk memilih opsi yang sesuai dengan keinginannya. Kuesioner menggunakan skala Likert.

Teknik analisis data dalam penelitian ini menggunakan Uji Validitas, Uji Reliabilitas, Uji Heterodiaksitas, dan Uji T. Teknik analisis data tersebut digunakan untuk mengetahui variable mana yang paling dominan didalam peneltiian. Diharapkan variable tersebut dapat dioptimalkan lebih lanjut oleh UMKM dalam memasarkan produknya

\section{HASIL PENELITIAN}

Untuk memperoleh kelengkapan data, penelitian ini mengunakan google form sebagai alat bantu untuk menyebarkan dan membagikan kuesioner kepada responden secara online. Adapun karakteristik responden meliputi nama, jenis kelamin, usia, dan repeat order shopee food. Hasil yang diperoleh dari kuesioner, mayoritas responden adalah Wanita (75\%), rentang usia $30-40(61 \%)$ dan melakukan pembelian di Shopee food lebih dari 2 kali $(86 \%)$.

Berdasarakan tabel 1 dapat disimpulkan bahwa semua $\mathrm{R}$ hitung lebih besar daripada $\mathrm{R}$ tabel. Ini menunjukkan bahwa seluruh unit dalam pernyataan kuesioner valid. Selanjutnya, berdasarkan tabel 2, dapat diketahui bahwa semua item pernyataan memiliki nilai Cronbach's alpa lebih dari 0,7. Hal ini membuktikan alat ukur yang digunakan dalam penelitian ini sudah reliable.

Berdasarkan hasil uji heteroskedastisitas pada tabel 3 diketahui bahwa besarnya nilai signifikansi variabel diskon (X1) sebesar 0,225, variabel cash back (X2) sebesar 0,149, variabel Shopee pay (X3) sebesar 0,196 yang lebih besar dari 0,05 atau $5 \%$, sehingga dapat disimpulkan bahwa model regresi bebas dari heteroskedastisitas. Berdasarkan tabel 4 hasil 
Uji t diatas dapat diketahui bahwa t hitung lebih besar daripada t tabel, maka hipotesis diterima. Diskon, cash back dan shopee pay memberikan pengaruh yang positif terhadap minat beli konsumen.

Tabel 1. Tabel Uji Validitas

\begin{tabular}{|c|c|c|c|c|}
\hline Variabel & Item & R hitung & $\mathrm{R}$ tabel & Ket \\
\hline Diskon & X1.1 & 0,856 & & 0,196 Valid \\
\hline \multirow[t]{3}{*}{$\mathrm{X} 1$} & $\mathrm{X} 1.2$ & 0,774 & & 0,196 Valid \\
\hline & $X 1.3$ & 0,726 & & 0,196 Valid \\
\hline & $\mathrm{X} 1.4$ & 0,609 & & 0,196 Valid \\
\hline Cash back & $\mathrm{X} 2.1$ & 0,845 & & 0,196 Valid \\
\hline \multirow[t]{3}{*}{$x 2$} & $X 2.2$ & 0,691 & & 0,196 Valid \\
\hline & $X 2.3$ & 0,683 & & 0,196 Valid \\
\hline & $X 2.4$ & 0,714 & & 0,196 Valid \\
\hline Shopee pay & X3.1 & 0,851 & & 0,196 Valid \\
\hline \multirow[t]{3}{*}{$x 3$} & X3.2 & 0,721 & & 0,196 Valid \\
\hline & X3.3 & 0,654 & & 0,196 Valid \\
\hline & X3.4 & 0,607 & & 0,196 Valid \\
\hline Minat beli & Y1 & 0,852 & & 0,196 Valid \\
\hline \multirow[t]{3}{*}{ Y } & Y2 & 0,739 & & 0,196 Valid \\
\hline & Y3 & 0,758 & & 0,196 Valid \\
\hline & Y4 & 0,673 & & 0,196 Valid \\
\hline
\end{tabular}

Sumber: data diolah

Tabel 2. Uji Realibilitas

\begin{tabular}{|l|l|l|}
\hline Variabel & Nilai Cronbach's Alpa & Keterangan \\
\hline Diskon & 0,885 & Reliable \\
\hline Cash back & 0,761 & Reliable \\
\hline Shopee pay & 0,759 & Reliable \\
\hline Minat beli & 0,769 & Reliable \\
\hline
\end{tabular}

Sumber : data diolah

Tabel 3. Uji Heteroskedastisitas

\begin{tabular}{|l|r|r|}
\hline Variabel & Nilai Alpha & Signifikansi \\
\hline Diskon & 0,05 & 0,225 \\
\hline Cash back & 0,05 & 0,149 \\
\hline Shopee pay & 0,05 & 0,196 \\
\hline
\end{tabular}

Tabel 4. Hasil Uji T

\begin{tabular}{|l|r|c|l|l|}
\hline Variable & Thitung & T tabel & Sig & Interpretasi \\
\hline Diskon & 3.764 & $1,98.000$ & H1 diterima \\
\hline Cash back & 2.991 & $1,98.025$ & H2 diterima \\
\hline Shopee pay & 2.163 & $1,98.359$ & H3 diterima \\
\hline
\end{tabular}





\section{PEMBAHASAN}

Menurut Staton\&Kritiawan (2018), potongan harga atau diskon adalah hasil pengurangan dari harga dasar atau harga tercatat atau harga harga terdaftar pengurangan dapat berbentuk harga yang dipotong atau konsesi lain seperti sejumlah barang gratis. Hipotesis pertama, yaitu diskon berpengaruh terhadap keputusan pembelian, diterima dan terbukti diskon memiliki pengaruh yang positif terhadap keputusan pembelian. Hal ini dapat dilihat dari hasil analisis Uji R , sebesar 0,885. Variabel diskon mempunyai pengaruh bagi konsumen dalam melakukan pembelian barang. Pengguna Shopee sebelum membeli suatu barang atau bertransaksi akan melakukan searching terlebih dahulu untuk mencari informasi toko di Shopee yang sedang mengadakan program diskon secara berkala. Dalam aplikasi ecommerce Shopee, diskon yang diberikan berupa potongan harga mulai dari $10 \%$ hingga $70 \%$, tergantung kebijakan setiap penjual. Dan tentu saja hal tersebut sudah dikonfirmasikan ke pihak Shopee, sehingga diskon akan muncul di fitur toko penjual ketika pembeli melihat toko tersebut melalui aplikasi Shopee. Hasil penelitian ini searah dengan penelitian yang dilakukan oleh (Denok, 2019) penerapan diskon dapat memberi dampak minat beli terhadap konsumen. Diskon merupakan daya tarik bagi konsumen untuk melakukan pembelian disebuah toko.

Cash back (Zainuddin, 2019) adalah daya tarik yang dapat dilakukan dalam meningkatkan volume penjualan yaitu dengan mengiming - imingi konsumen atas pengembalian sejumlah perorbanan yang dilakukan dengan syarat tertentu Hipotesis kedua, yaitu cash back berpengaruh positif terhadap keputusan pembelian, diterima dan terbukti bahwa cash back memberikan pengaruh yang positif terhadap keputusan pembelian. Dapat dilihat dari hasil analisis uji $\mathrm{R}$, cash back memberikan pengaruh sebesar 0,761. Cash back yang diberikan oleh Shopee berupa potonga harga ketika konsumen sudah melakukan pembelian, dan ada juga cash back berupa point shopee. Yang nantinya point ini dapat digunakan untuk memotong pembayaran konsumen ketika melakukan pembelian barang di Shopee. Hal ini sejalan dengan penelitian
Fitri (2021) yang menyatakan bahwa ada pengaruh secaa signifikan antara cashback dan minat menggunakan shopee. Responden menyukai adanya suatu promosi yang diberikan yaitu cash back. Cash back mempengaruhi minat konsumen dalam melakukan pembelian ulang sebuah produk.

Shopee pay adalah fitur yang terdapat dalam aplikasi Shopee dan bisa digunakan untuk melakukan pembayaran online. Hipotesis ketiga yaitu Shopee pay berpengaruh positif terhadap keputusan pembelian, diterima dan terbukti. Shopee pay adalah sistem pembayaran yang ada di fitur Shopee dan bisa digunakan untuk melakukan pembayaran pada saat konsumen melakukan transaksi apapun melalui Shopee. Sebelum digunakan Shopee pay harus diisi terlebih dahulu menggunakan mata uang rupiah. Dapat dilihat dari analisis uji $\mathrm{R}$, nilai Shopee pay adalah 0,759 . Hal ini sejalan dengan penelitian yang dilakukan oleh Kadek (2021) yang menyatakan bahwa Shopee pay memberikan pengaruh terhadap minat beli konsumen. Penawaran yang diberikan oleh pihak Shopee melalui fitur Shopee pay contohnya konsumen bisa membeli kopi seharga Rp.1, tentu saja ini sangat menarik konsumen untuk mengisi shopee pay mereka kemudian melakukan pembelanjaan.

\section{SIMPULAN, KETERBATASAN, SARAN}

\section{Simpulan}

Berdasarkan hasil analisis hipotesis yang sudah dilakukan, maka dapat disimpulkan bawah : 1). Variabel diskon memberikan pengaruh positif dan signifikan terhadap keputusan pembelian konsumen. Semakin besar sebuah toko memberikan diskon, maka tingkat pembelian ulang yang dilakukan oleh konsumen semakin tinggi. Merchant yang sudah bekerja sama dengan Shopee bisa memberikan penawaran diskon yang menarik terhadap konsumen. Banyak toko yang memberikan diskon mulai dari 20\& hingga $50 \%$ jika melakukan pembelian sejumlah tertentu. Konsumen lebih sering melihat apakah sebuah toko memberikan diskon atau tidak sebelum memutuskan untuk membeli. 2). Variabel Cash back memberikan pengaruh 
yang positif dan significant terhadap keputusan pembelian. Cash back yang ditawarkan oleh Shopee sangat menarik konsumen. Contohnya adalah beberapa UMKM menerapkan cash back ditoko mereka, dengan menawarkan kepada konsumen jika melakukan pembelian sebesar tertentu maka konsumen akan menerima cash back senilai yang sudah ditetapkan oleh toko. Cash back di shopee berupa deposit, yang nantinya bisa digunakan untuk melakukan pembayaran untuk semua transaksi yang dilakukan melalui shopee. 3). Variabel Shopee pay memberikan pengaruh yang positif dan significant terhadap keputusan pembelian. Seorang pengguna baru di Shopee jika membuka Shopee pay mereka, akan mendapatkan penawaran pembelian produk yang pembayarannya menggunakan shopee pay. Harga produk menjadi lebih murah dari harga pasaran. Merchant shopee memberikan daya tarik shopee pay melalui harga yang lebih murah, contohnya konsumen dapat membeli roti dengan harga Rp. 1, dan tentunya pembayaran melalui shopeepay. Fitur - fitur diskon, cash back dan shopee pay ini sangat menarik minat konsumen dalam memutuskan pembelian sebuah produk, terutama produk makanan.

Dari kesimpulan diatas maka penelitan tujuan Optimalisasi Aplikasi Ecommerce Shopee Food sebagai Media Pemasaran UMKM dimasa Pandemi Covid 19 dapat dibuktikan melalui hasil uji hipotesis yang sudah dilakukan. Dari hasil uji hipotesis dapat dilihat bahwa UMKM yang memanfaatkan fitur - fitur di Shopee yaitu diskon, cash back dan shopee pay mampu bertahan dimasa pandemic

\section{DAFTAR REFERENSI}

Adil Fadillah, Rini Syarif (2013). Pengaruh Program Diskon Terhadap Keputusan Pembelian. Jurnal Ilmu Manajemen Kesatuan, 1(1).

Daniel, Olivia (2021). Pengaruh Public Relation, Advertising, dan Word Of Mouth Terhadap Brand Awareness Produk UMKM : Studi Kasus Pada Toko $X$ Cake An Bakery. Jurnal Riset Manajemen dan Bisnis, 16 (1). covid 19 karena konsumen memutuskan membeli produk berdasarkan variable tersebut. Semakin sering UMKM melakukan promo menarik lewat aplikasi Shopee food, maka konsumen akan melakukan repeat order ditoko yang sama.

\section{Ketebatasan}

Peneliti memiliki keterbatasan dalam melaksanakan penelitian. Diantaranya : 1). Populasi yang digunakan kurang luas, hal ini dikarenakan adanya pandemic covid 19, menyebabkan ruang lingkup peneliti menjadi terbatas. 2). Kendala pandemic yang menyebabkan peneliti kurang optimal dalam terjun langsung ke responden, sehingga penyebaran kuesioner hanya melalui google form tanpa melakukan observasi ke lapangan. 3). Keterbatasan teori yang dimiliki oleh peneliti menyebabkan penyampaian teori dalam penelitian kurang lengkap.

\section{Saran}

Berdasarakan kesimpulan diatas, disarankan peneltiian selanjutnya dapat menggunakan varibel lain yang lebih up to date, seperti shopee pay later. Dan untuk populasi bisa diperluas tidak hanya di Kota Surakarta saja. Penelitian selanjutnya diharapkan dapat menggunakan tambahan metode lain selain kuesioner untuk memperoleh hasil yang lebih maksimal, misalkan menambahkan metode observasi dan wawancara.

Denok Wahyu (2019). Penerapan Diskon Dalam Menarik Minat Beli Konsumen Di Matahari Departement Store Kediri Town Square. Jurnal Ilmu - ilmu Ekonomi, 12 (2).

Dewi D Fakhriyyah, Arista Fauzi K.S, Lucky Ayu Damayanti, Mardhani Susilawati (2021). Perluasan Pangsa Pasar Produk UMKM Selama Pandemi Covid-19 Melalui Pemanfaatan Marketplace. 
Jurnal Pembelajaran Pemberdayaan Masyarakat, 2 (3).

Fitri M, Renny D. (2021). Pengaruh Persepsi Kemudahan Penggunaan Dan Promosi Cashback Terhadapa Minat Mahasiswa Dalam Menggunakan Dompet Digital Shopeepay Pada Aplikasi Shopee. Jurnal Pendidikan Tata Niaga. 9 (3).

Fitriani L, Dirwan, Muhammad I. (2021). Determinan Minat Penggunaan E-wallet Shopeepay. Jurnal Ilmiah MEA. 5 (3).

Jay Abraham (2019). The Sticking Point Solution. Vanguard Press.

John Westwood (2010). How to Write a Marketing Plan. Kogan Page Publisher

Kadek I, I Gusti Ayu K.S.R.D (2021). Pengaruh Nilai, Harga, Literasi Keuangan Dan Kemampuan Finanasial Terhadap Minat Penggunaan Dompet Digital (Shopeepay) Dalam Transaksi Keuangan (Studi Kasus Pada Mahasiswa S1 Akuntansi Universitas Pendidikan Ganesha). Jurnal Ilmiah Mahasiswa Akuntansi, 12 (3).

Oktavianus (2020). Analisis Pengaruh Harga dan Kualitas Layanan Elektronik Terhadap Kepuasan Konsumen Pada Pengguna Aplikasi Shopee. Jurnal Ilmu Manajemen, 8 (4).
Patricia Felita, Elsie Oktivera (2019). Pengaruh Sales Promotion Shopee Indonesia Terhadap Impulsive Buying Konsumen Studi Kasus : Impulsive Buying Pada Mahasiswa STIKS Tarakanita. Jurnal Ilmu Komunikasi dan Bisnis, 4 (2).

Philip Kotler (2019). Principle of Marketing. Pearson.

Rahmatika (2021). Pengaruh Penggunaan Paylater Terhadap Perilaku Impulse Buying Pengguna E-Commerce di Indonesia. Jurnal Riset Bisnis dan Investasi, 7 (1).

Shabur Miftah Maulana,Heru Susilo, Riyadi (2015). Implementasi E-commerce Sebagai Media Penjualan Online (Studi Kasus Pada Toko Pastbrik Kota Malang. Jurnal Bisnis, 29 (1).

Sugiyono. (2017). Metode Penelitian Manajemen. Bandung: Alfabeta.

Zainuddin, Nilam Cahya (2019). Pengaruh Promo Penjualan dan Cashback Terhadap Minat Beli Kendaraan Pada PT. Hadji Kalla Palopo. Journal of Institution and Sharia Finance, 2 (2).

\section{Copyrights}

Copyright for this article is retained by the author(s), with first publication rights granted to the journal.

This is an open-access article distributed under the terms and conditions of the Creative Commons Attribution license (http://creativecommons.org/licenses/by/4.0/). 